\section{Genetics and ethics in China}

SIR - In response to the article on the Chinese Maternal and Infant Health Care Law (Nature 383, 204; 1996), I should like to clarify the position of the International Genetics Federation (IGF) on the relation between the so-called 'eugenics law' and the 1998 International Genetics Congress, to be held in Beijing.

One important task of the IGF is to sponsor and oversee the administration of international genetics congresses. At the 1993 Birmingham Congress, the representative council of the IGF, composed of delegates from genetical societies worldwide, voted to hold the next congress in Beijing.

Subsequently, when the new Chinese law was passed, the executive council of the IGF decided that the best way to deal with the genetical and ethical issues that are inherent in it was to encourage a full debate among geneticists. The Beijing Congress seemed (and still seems) the best venue for such a debate. The executive therefore asked the local organizing committee in Beijing to include a symposium on eugenics in the programme. The committee agreed and the symposium will be organized by Dr Robert Haynes, who was president of the highly successful 1989 congress in Toronto. (Haynes has never held a position in the IGF, as you claim.)

You reported on a statement issued by eminent human geneticists at the 9th International Congress of Human Genetics (Rio de Janeiro, 1996) calling for a delay in implementing the Chinese law, and a moratorium on the drafting of similar laws in other countries pending discussion by geneticists. This statement is perfectly in accord with the notion of using the Beijing Congress as a platform for an international debate on these serious issues.

You also reported the result of a ballot circulated to members of the British Genetical Society on a motion proposing suspension of the society's affiliation with the IGF as a protest against its decision to hold the next congress in Beijing. The result was that 56 individuals voted for and 44 against the motion (not 60 to 40 as you reported).

This result must be treated cautiously. First, the sample size was small (about 6\% of the membership). Such a small return could be interpreted in several ways, but the danger is that the sample is not representative. Second, before considering disaffiliation from the IGF, the Genetical Society should note that the IGF is active in other aspects of genetics at the international level. It provides small grants for local conferences in poor countries, supports travel by young geneticists to international genetics congresses, and has initiated schemes to promote worldwide education in genetics and to provide partnerships between geneticists in rich and poor countries. All these would be affected adversely by withdrawal of support of one of the world's largest societies.

Third, the protest seems misplaced. The IGF can act only through the constraints of its constitution and did so. If changes in the constitution are required, then member societies can propose them and vote for them. Furthermore, impeding the success of the Beijing Congress would hurt participating groups that seem unlikely to be the true targets of the protest. Chinese and other geneticists would be deprived of an important opportunity to hear and meet the world's best scientists.

Genetics and ethics have always been intertwined. We should use the international gathering in 1998 to explore and debate this relationship in the complex and controversial area of eugenics, and together arrive at comprehensive set of recommendations to governments worldwide. For such recommendations to carry the full weight of authority, it is important that all genetical societies attend and participate.

\section{A. J. F. Griffiths}

(Secretary, International

Genetics Federation)

University of British Columbia,

Vancouver, BC, Canada

e-mail: agriff@unixg.ubc.ca

\section{Shells suitable}

SIR - Daedalus proposes that chitin fibres and bulk chitin polymer might be produced from crab shells (Nature 382, 498; 1996). This has already been done by Professor Seiichi Tokura at the Graduate School of Environmental Earth Sciences of Hokkaido University, Sapporo, Japan. Tokura routinely produces both very strong chitin fibres and thin chitin sheets from crab shells.

The fibres are very useful for stitching after surgical operations, because they are completely absorbed by the human body and do not have to be physically removed. Similarly, the chitin sheets serve as bandages for bleeding wounds. It is often difficult to remove ordinary bandages, which stick to a wound because of clotted blood, but the chitin bandages are simply absorbed into the body, and more layers can be applied until the wound has healed. There are, of course, many other potential uses of crab chitin, and many of these are being developed by Tokura.

\section{Harmon Craig}

Scripps Institution of Oceanography,

University of California, San Diego,

La Jolla, California, 92093-0220, USA

\section{Shiny Sheffield}

SIR - I was disappointed by the photograph of Sheffield that you used to illustrate your recent News story on British government plans to cut air pollution by 2005 (Nature 382, 743; 1996).

The photograph was clearly taken some years ago. Sheffield is now rightly regarded

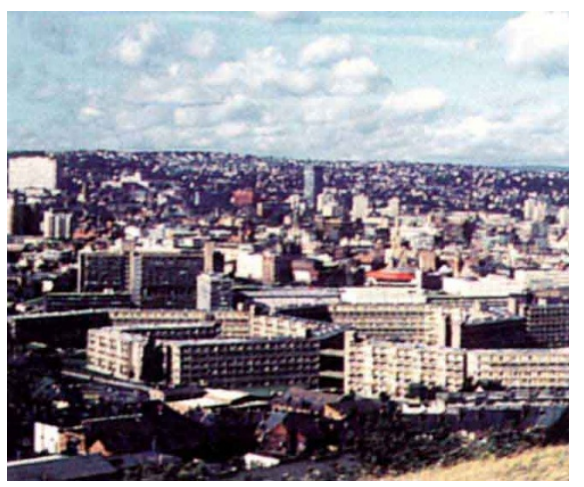

In the clear: Sheffield looks like this now.

as one of Europe's cleanest industrial cities and is pioneering new ways of ensuring management and sustainability of air quality. To that end, we have been acting as a pilot for the government's draft strategy that you reported, and we have just received European funding to assist our work.

\section{Frank R. Price}

Environmental Protection Service,

Sheffield City Council,

1 Barkers Pool,

Sheffield S1 1EN, UK

\section{Multiple author}

SIR - I have been wondering about the law of priority for names of authors of papers. I am one of those relatively rare males who have a problem that is all too common among females - I have changed my name since I started publishing.

One solution is to continue to use the 'maiden' name (J. T. Clark), but having decided to abandon my first surname this is not one for me to adopt. I have tried as far as possible to use both surnames in published articles (J. T. Clark Sellick) to get some form of continuity, but this gets me extracted in indexes as Clark, Sellick and even Clarksellick. Some journals, however, now insist on just first name and surname (John Sellick), so that neither previous surname nor familiar initials provide any continuity.

Can anybody recommended a solution? I was inspired to pen this note by seeing a footnote to a citation that read "Clark is a senior name to Sellick".

J. T. C. Sellick

Montemassi, 31 Regent Street,

Kettering,

Northants NN16 8QG, UK 